REVIEW

\title{
Early Lung Cancer: screening and detection
}

\section{Catherine Read*, Sam Janes, Jeremy George, Stephen Spiro}

\author{
Department of Thoracic Medicine, University College London Hospitals NHS Foundation Trust, \\ Grafton Way, London WC1E 5DB, United Kingdom
}

Received 27 September 2006; accepted 29 September 2006

\section{KEYWORDS \\ Lung cancer; \\ Diagnosis; \\ Screening; \\ Detection; \\ Fluorescence; \\ Bronchoscopy; \\ Sputum cytometry}

\begin{abstract}
Summary The most significant factor which determines the survival of a patient newly-diagnosed with lung cancer is the stage at which the disease has been diagnosed. Late diagnosis is common. This review focuses upon the possibility of earlier diagnosis using various cytological and radiological imaging techniques such as sputum cytology or cytometry, CT scanning, and fluorescence bronchoscopy.

(c) 2006 General Practice Airways Group. Published by Elsevier Ltd. All rights reserved.
\end{abstract}

\section{Contents}

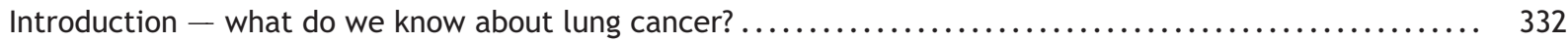

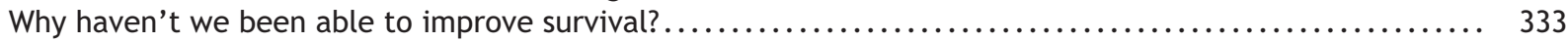

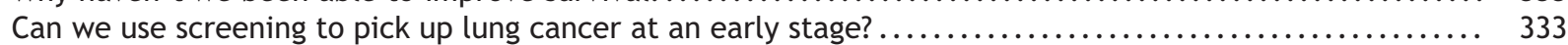

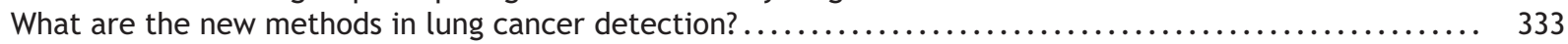

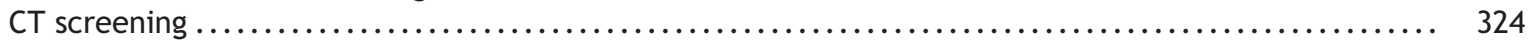

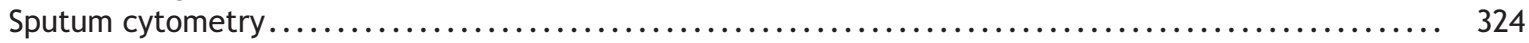

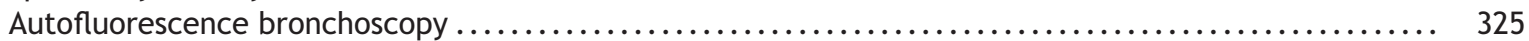

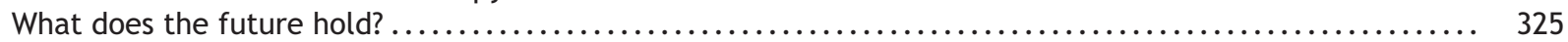

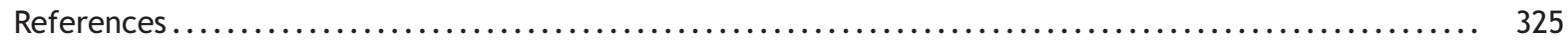

\section{Introduction - what do we know about lung cancer?}

Lung cancer is the world's most common fatal cancer and the second most common cancer in the UK, accounting for more than 33,000 deaths per

\footnotetext{
* Corresponding author. Tel.: +44 (0)207 380 9004; fax: +44 (0)207380 9476 .

E-mail address: catherine.read@uclh.nhs.uk (C. Read).
}

annum [1]. This amounts to more deaths than those from cancers of the colon, breast and prostate combined.

In the past 30 years, significant progress has been made in the treatment of many cancers. For example, the five-year survival for breast cancer has increased from $75 \%$ in $1974-1976$ to $88 \%$ during 1995-2000. In contrast, the five-year survival rate for lung cancer was $13 \%$ during $1974-76$ and was $15 \%$ in $1995-2000$. 
The majority of lung cancer cases are believed to be related to tobacco smoking $(80-90 \%)$ and it is noteworthy that despite the link between smoking and lung cancer which was published in epidemiological studies over fifty years ago [2], lung cancer remains our biggest cause of potentially avoidable cancer death.

\section{Why haven't we been able to improve survival?}

The most significant factor for survival in lung cancer is the stage of disease at diagnosis [3]. This is entirely dependent upon how early in its development the tumour is diagnosed. Lung cancer tends not to cause symptoms in its early stages, whilst in patients with more advanced disease symptoms are non-specific. It is therefore classically picked up late in its development.

A simple consideration of the natural history of lung cancer puts the problem of late diagnosis in perspective. It is estimated that a tumour of $1 \mathrm{~mm}$ in size is halfway through its growth cycle, and at $3-4 \mathrm{cms}$ (average size at time of diagnosis) it is more than three-quarters of the way through its growth cycle. Plenty of time will have elapsed for metastatic spread before the cancer is diagnosed by conventional methods. At a cellular level, an in situ carcinoma is defined as neoplasia that has not penetrated the basement membrane of the mucosa. The first signs of invasive cancer are invasion of the basement membrane and infiltration of malignant cells into the underlying connective tissues and blood vessels. This process may take between 10 and 20 years to develop [4].

Presenting symptoms can range from cough and haemoptysis to chronic and repeated chest infections. These early symptoms are difficult to distinguish from a minor illness [5]. The mortality of lung cancer at five years is now 85 to $90 \%$. The reality is that, of 100 patients who present with lung cancer, 80 will be found to be inoperable because they have widespread disease or significant co-morbidity, and about 20 will be put forward for a surgical resection which is the treatment of choice; of these around 15 will undergo "curative resection" and only 5 to 10 of these will be alive and disease-free at five years [6].

\section{Can we use screening to pick up lung cancer at an early stage?}

If screening per se is to be successful, there are some basic assumptions that have to be met: (a) the proposed intervention should reduce mortality in the screened group in comparison with the unscreened group; and (b) the sensitivity, specificity, availability and the cost, together with the associated morbidity of the screening tests must be deemed reasonable [7].

Sputum screening for lung cancer is an area that has been significantly researched by different groups. In the 1970s, sputum cytology was mooted as the new non-invasive screening revolution for lung cancer. Over the next decade there were three large randomized controlled trials (RCTs) in lung cancer screening sponsored by the National Cancer Institute $(\mathrm{NCl})$ in the USA. These were carried out to evaluate screening with annual chest $\mathrm{x}$-rays and also analysis of sputum cytology at set intervals [8-10], but again there was no reduction in lung cancer mortality. However, these trials did discover more early stage lung cancers suitable for curative treatment (typically surgery), together with an improved 5-year survival in the screened arms, but there was no overall improvement in mortality.

Later, Saccomanno et al. collected sputum samples from workers in uranium mines deemed to be at high risk for developing lung cancer [11]. Their sputum was found to harbour atypical cells, and patients with these abnormalities over time developed lung cancer. The link between abnormal sputum cytology and lung cancer development has been subsequently confirmed in other studies [12-14]. So why was sputum screening found to be futile in the $\mathrm{NCl}$ trials? From these data it has been suggested that sputum cytology and chest $\mathrm{x}$ ray are not sensitive enough to detect cancers at sufficiently early stages.

The early trials had a consistently negative impact on screening. As a consequence, screening was not recommended by any advisory group. However, interest has continued in the development of diagnostic tests which have greater sensitivity, and which could be incorporated into future screening programmes.

\section{What are the new methods in lung cancer detection?}

The results of the early trials of chest $x$-ray and sputum cytology analysis have clearly been disappointing. However, there has been progress in the field of early detection. We now have a greater knowledge of the patient groups who are at risk of developing lung cancer and are able to identify the subgroups of smokers with an extremely high risk of developing the disease; these include smokers 
with COPD, those with previous cancers of the aerodigestive tract, and those with a history of asbestos exposure.

In addition, there is growing evidence to suggest that an individual's susceptibility to developing lung cancer may be affected by genetic inheritance. A large population study, GELCAPS, is now being undertaken in the UK to identify these predisposing genetic factors.

There have been recent important advances in radiological imaging. Although it has long been appreciated that chest radiography lacks sufficient sensitivity for screening, computed tomography (CT) enables very much smaller lesions to be detected. A chest $x$-ray can reveal tumours in the region of $3 \mathrm{cms}$, whereas $C T$ can pick up tumours as small as $0.5 \mathrm{cms}$. Until recently, the slow scanning times and high radiation exposure of CT made it an unsuitable tool for screening. However, with the development and refinement of spiral CT, it has become possible to reduce significantly scanning times and radiation exposure. Preliminary results have been most encouraging, such that $80-90 \%$ of CT screen-detected bronchial carcinomas are diagnosed as early stage 1 tumours [15-17].

These figures compare well with figures of $5-15 \%$ for populations that have not been screened, and advocates of CT screening state that this is sufficient justification to use CT alone. However, others have argued that the evidence is not sufficiently robust as it does not make allowances for either lead-time or overdiagnosis bias. The value of CT screening will be demonstrated when a stage shift is observed where the increased detection of early stage I and II disease is matched by a decrease in late stage III and IV disease. We continue to wait for this evidence.

\section{CT screening}

CT can miss early tumours situated within the central airways but it can detect peripheral tumours of the lung reliably. Screening studies for lung cancer with low-dose spiral CT scanning have the ability to identify peripheral nodules of a few millimetres in diameter, although the majority of these ultimately are shown to be benign. The pivotal study by Henschke et al. published this year looked at the incidence of pulmonary nodules in asymptomatic people at high risk for lung cancer who were invited to undergo $\mathrm{CT}$ screening [17]. They found 28 new cancers in 1000 healthy volunteers with at least a 20 pack-year smoking history, but they also found 233 benign nodules. As a result an algorithm was devised for the follow-up and investigation of these nodules, according to their size.

Similar hypothesis-generating $\mathrm{CT}$ studies have taken place in Japan. The smoking history and other risk factors have varied between studies, but cancers have been found in $2.8-1.4 \%$ of subjects on their prevalence screen, with far fewer identified on the subsequent annual incidence CTs. Studies with older subjects have found that greater smoking histories and patients with airflow obstruction have a higher prevalence of new cancers. There are now a number of prospective RCTs of CT screening versus nothing or an annual chest $\mathrm{x}$-ray, in progress. The largest is the 50,000-patient $\mathrm{NCl}$ study in the USA [18], with several smaller, similar studies currently recruiting in Europe. Once these studies are complete it will take 10 years of follow up to see if lung cancer mortality will be changed in the active arm of each study.

\section{Sputum cytometry}

The diagnostic yield of sputum cytology is known to vary in relation to tumour location. It has greatest use in the identification of central tumours and is of little or no value in the identification of peripheral cancers [19]. However, there is now evidence to suggest that its sensitivity can be much improved through the use of molecular genetic and immunocytochemical markers of malignancy.

Sputum samples obtained during the $\mathrm{NCl}$ sponsored screening programme at Johns Hopkins were banked in an archive, allowing investigators to evaluate more recently-developed tumour markers using material where the eventual clinical outcome is known. Such studies have shown that abnormal cells may be recognised in sputum up to 20 months before a lung cancer diagnosis was made. In addition, there is now evidence to suggest that the sensitivity of sputum screening may be significantly enhanced by the use of computer-assisted image analysis (automated image cytometry). This technique is able to analyse quantitatively the nuclear structure and DNA content of an individual cell [20]. Xing et al. demonstrated in their study of 2,480 smokers the ability to detect prevalence lung cancers in 27 patients, of whom 25 provided sputum samples for analysis [21]. Sputum samples from twenty of these patients (80\%) were positive using cytometry as compared with only one $(4.2 \%)$ with conventional cytology, demonstrating a 20 -fold increase in sensitivity. The study was also able to detect severe dysplasia/carcinoma in situ lesions. As sputum cytometry successfully detected 8 out of 11 adenocarcinomas, this technique may be of 
value in detecting cancers situated in both the central and peripheral airways.

\section{Autofluorescence bronchoscopy}

The increased sensitivity of sputum tests to detect exfoliated cells from early lung cancers will place a greater onus on the bronchoscopist to find early lung cancers in the large airways. This has led to the development of optical imaging devices such as autofluorescence bronchoscopy which have a higher sensitivity for detection of abnormal cells. This technique exploits the differences in the fluorescence properties of bronchial mucosa compared to mucosa of pre-invasive and invasive disease.

The LIFE (Lung Imaging Fluorescence Endoscopy) system, designed by Lam [22] is the best known instrument. This uses a blue $(442 \mathrm{~nm})$ heliumcadmium laser to illuminate the bronchial mucosa, and the resulting fluorescence is then digitised into a real-time video image. Other devices, such as the D-light auto-fluorescence system developed by Karl Storz [23], do not require image-intensifying cameras but use optical filters incorporated into the bronchoscope.

The majority of published studies on autofluorescence bronchoscopy have shown a significant increase in diagnostic sensitivity for dysplasia and carcinoma in situ detection [24-29]. In a recent meta-analysis of over 1,000 cases investigated with the LIFE device, the sensitivity of detection for such lesions was enhanced 1.8fold when compared with conventional white light detection [30]. There is also evidence to suggest that the detection of invasive carcinoma is enhanced by fluorescence bronchoscopy [24] and some groups now use this technique to assess patients with abnormal sputum cytology. In a recent study of 79 patients with moderate atypia, fluorescence bronchoscopy successfully identified three patients $(3.7 \%)$ with radiologicallyoccult invasive squamous cell carcinoma [31]. Importantly, the outlook for such early central lung cancers is extremely favourable with 5 -year survival rates ranging from $83-92 \%[32,33]$.

\section{What does the future hold?}

The parallel developments in radiology, molecular biology and optical imaging, provide the prospect of providing a screening model for detecting early lung cancers when the likelihood of cure through surgical intervention is very high. There has been encouraging progress made in our understanding of lung cancer risk factors and the prospect of reintroducing screening in highly selected groups is very real.

We are about to embark on a five-year randomised controlled surveillance study, starting in 2007 and funded by Cancer Research UK, looking at a high-risk population with mild or moderate COPD and a significant smoking history. The research will use the combined techniques of sputum cytology/cytometry, annual CT scans, and fluorescence bronchoscopy in an attempt to demonstrate detection of a large proportion of lung cancers at early stages when curative treatment is feasible. Our main aim will be to show that the proportion of lung cancers diagnosed at stage I or II is significantly greater in the surveillance arm than in the control arm. Surveillance may yet be the key to unlocking the door to early lung cancer detection.

\section{References}

[1] http://www.cancerresearchuk.org/aboutcancer/statistics/ mortality.

[2] Doll R, Hill AB. Smoking and carcinoma of the lung. Preliminary report. Br Med J 1950;2:739.

[3] Scagliotti G. Symptoms, signs and staging of lung cancer. Eur Respir 2001:86-119.

[4] http://www.cancerline.com/cancerlinehcp.

[5] Buccheri G, Ferrigno D. Lung cancer: clinical presentation and specialist referral time. Eur Respir J 2004;24: 898-904.

[6] Hamilton W, Peters TJ, Round A, Sharp D. What are the clinical features of lung cancer before the diagnosis is made? A population based case-control study. Thorax 2005;60(12):1059-65. Epub 2005 Oct 14.

[7] Patz Jr EF, Goodman PC, Bepler G. Screening for lung cancer. N Engl J Med 2000;343:1627-33.

[8] Fontana RS, Sanderson DR, Taylor WF, Woolner LB, et al. Early lung cancer detection: Results of the initial (prevalence) radiologic and cytologic screening in the Mayo Clinic study. Am Rev Resp Dis 1984;130:561-5.

[9] Frost JK, Ball WC, Levin ML, Tockman MS, et al. Early lung cancer detection: Results of the initial (prevalence) radiologic and cytologic screening in the Johns Hopkins study. Am Rev Resp Dis 1984;130:549-54.

[10] Flehinger BJ, Melamed MR, Zaman MB, Heelan RT, et al. Early lung cancer of the initial (prevalence) radiologic and cytologic screening in the Memorial Sloane-Kettering study. Am Rev Resp Dis 1984;130:555-60.

[11] Saccomanno G, Archer VE, Auerbach O, et al. Development of carcinoma of the lung as reflected in exfoliated cells. Cancer 1974;33:256-70.

[12] Prindiville SA, Byers T, Hirsch FR, et al. Sputum Cytological Atypia as a Predictor of Incident Lung Cancer in a Cohort of Heavy Smokers with Airflow Obstruction. Cancer Epidemiology, Biomarkers \& Prevention 2003;12: 987-93.

[13] Tockman MS, Gupta PK, Myers JD, Frost JK, Baylin SB, Gold EB, et al. Sensitive and specific monoclonal antibody recognition of human lung cancer antigen on preserved 
sputum cells: a new approach to early lung cancer detection. J Clin Oncol 1988;6:1685-93.

[14] Risse EK, Vooijs GP, van't Hof MA. Diagnostic significance of 'severe dysplasia' in sputum cytology. Acta Cytol 1988;32:629-34.

[15] Kaneko M, Eguchi K, Ohmatsu H, et al. Peripheral lung cancer: Screening and detection with low-dose spiral CT versus radiography. Radiology 1996;201:798-802.

[16] Swensen SJ, MD, Jett JR, Sloan JA, et al. Screening for lung cancer with low dose helical computed tomography. Am J Respir Crit Care Med 2002;165:508-13.

[17] Henschke $\mathrm{Cl}$, Lee IJ, Wu N, et al. CT screening for lung cancer: prevalence and incidence of mediastinal masses. Radiology 2006;239(2):586-90.

[18] http://www.cancer.gov/nlst/what-is-nlst.

[19] Thunnissen FBJM. Sputum examination for early detection of lung cancer. J Clin Pathol 2003;56:805-10.

[20] Marek W, Kotschy-Lang N, Muti A, et al. Can semiautomated image cytometry on induced sputum become a screening tool for lung cancer? Evaluation of quantitative semi-automated sputum cytometry on radon- and uraniumexposed workers. Eur Respir J 2001;18:942-50.

[21] Xing S, Khanavkar B, Nakhosteen JA, Atay Z, Jockel K$\mathrm{H}$, Merek $\mathrm{W}$. Predictive value of image cytometry for diagnosis of lung cancer in heavy smokers. Eur Respir J 2005;25:956-63.

[22] Lam S, MacAulay C, Hung J, et al. Detection of dysplasia and carcinoma in situ with a lung imaging fluorescence endoscope device. J Thorac Cardiovasc Surg 1993;105:1035-40.

[23] Leonhard M. New incoherent autofluorescence/ fluorescence system for early detection of lung cancer. Diagn Therap Endosc 1999;5:71-5.

[24] Lam S, Kennedy $T$, Unger $M$, et al. Localization of bronchial intraepithelial neoplastic lesions by fluorescence bronchoscopy. Chest 1998;113:696-702.
[25] Vermylen P, Pierard P, Roufosse C, et al. Detection of bronchial preneoplastic lesions and early lung cancer with fluorescence bronchoscopy: a study about its ambulatory feasibility under local anaesthesis. Lung Cancer 1999;25:161-8.

[26] Venmans BJ, van Boxem AJ, Smit EF. Results of two years experience with fluorescence bronchoscopy in detection of pre-invasive bronchial neoplasia Diagn. Therap Endosc 1999;5:77-84.

[27] Ikeda N, Kim K, Okunaka T, et al. Early localisation of bronchogenic cancerous/precancerous lesions with lung imaging fluorescence endoscope Diagn. Therap Endosc 1997;3:197-201.

[28] Yokomise H, Yanagihara K, Fukuse T, et al. Clinical experience with lung-imaging fluorescence endoscope (LIFE) in patients with lung cancer. $J$ Bronchol 1997;4:205-8.

[29] Hirsch FR, Prindiville SA, Miller YE, et al. Fluorescence versus white-light bronchoscopy for detection of preneoplastic lesions: a randomized study. J Natl Cancer Inst 2001;93:1385-91.

[30] Lam S, MacAulay C, LeRiche JC, et al. Detection and localization of early lung cancer by fluorescence bronchoscopy. Cancer 2000;89(Suppl):2468-73.

[31] Kennedy TC, Franklin WA, Prindiville SA, et al. High prevalence of endobronchial malignancy in high-risk patients with moderate sputum atypia. Lung Cancer 2005;49:187-91.

[32] Saito Y, Nagamota N, Shin-Ichiron O, et al. Results of surgical treatment from roentgenographically occult bronchogenic squamous cell carcinoma. J Thorac Cardiovasc Surg 1992;104:401-7.

[33] Bechtel JJ, Kelley WR, Petty TL, et al. Outcome of 51 patients with roentgenographically occult lung cancer detected by sputum cytology testing. Arch Intern Med 1994;154:975-80.

Available online at www.sciencedirect.com 